\title{
ICAO Overloading Practice versus Airport Pavement Design Life Using FAARFIELD 1.3 and COMFAA 2.0, 3.0
}

\author{
Ahmed Mohamady Abdallah Wahba* \\ Department of Civil Engineering, Faculty of Engineering, Zagazik University, Zagazik, Egypt \\ *Corresponding author: dr_amohamady@yahoo.com
}

\begin{abstract}
The objective of the study is to evaluate the impact of New Large Aircraft (NLA) on airport flexible pavement versus overloading in ICAO Practice. The study is conducted using Hurghada, Egypt Airport air fleet composition at four annual departure levels, four standard subgrade strength categories, and adding NLA at five different percentages. On the basis of the results of this research, it is concluded that, The statement in ICAO Practice "the annual number of overload movement should not exceed approximately 5 per cent of total annual aircraft movement" must be re-evaluated due to many factors as new large aircraft type ,annual departures and soil characteristics which High reduction in pavement life that has an average of $8.2 \%$ of 20 years design life due to introduction of A380-800 by 5\% of annual departures, occurred at 3\% CBR ., and The statement in ICAO Practice "For flexible pavement occasional movement by aircraft with Aircraft Classification number (ACN) not exceeding 10 per cent above the reported Pavement Classification number (PCN) should not adversely affect the pavement" must be re-evaluated because there is no restriction for adding new large aircraft with 5\% Annual departure at any annual departures, soil characteristics comparing between COMFAA 2,3 software which High reduction in pavement life that has an average of $8.2 \%$ of 20 years design life due to introduction of A380-800 by $5 \%$ of annual departures, occurred at 3\% CBR.
\end{abstract}

Keywords: airports, new large aircraft, flexible pavements, ICAO overloading, operational pavement life, COMFAA, FAARFIELD

Cite This Article: Ahmed Mohamady Abdallah Wahba, "ICAO Overloading Practice versus Airport Pavement Design Life Using FAARFIELD 1.3 and COMFAA 2.0, 3.0.” American Journal of Civil Engineering and Architecture, vol. 5, no. 2 (2017): 57-65. doi: 10.12691/ajcea-5-2-5.

\section{Introduction}

The new large aircraft's physical and operational characteristics will therefore dictate the design of future airports and their facilities. As the characteristics of the aircraft increase, an airport's category may have to be increased to the next higher level. Newer generations of airplanes generally have an impact on existing airport facilities and services when the dimensions and/or mass of these airplanes exceed the design parameters used for planning and developing an airport. Consequently, as such newer and larger airplanes entered commercial service, airport evolved by making necessary modifications to comply with the applicable ICAO Annex 14 specifications, as updated from time to time. In certain cases, such modifications may not be considered practicable. In such cases, in order to ensure that a new airplane can be safely operated, States should carry out appropriate aeronautical studies to evaluate the suitability of existing facilities and to determine the need for alternative measures, operational procedures and operating restrictions for the specific airplane concerned. Some States and international organizations have already undertaken such studies tailored to a specific airplane type, to determine if solutions can be developed for those existing aerodromes which may not be able to comply fully with the code $\mathrm{F}$ provisions for the introduction of the NLA concerned. The increased mass and/or gear load of the NLAs would require adequate pavement support. The pavements meant for heavy aircraft usually have a bituminous bound wearing course. A flexible pavement yields more under surface loading merely accomplishing a widening of the loaded area and consequent reduction of pressure layer by layer. Existing pavements would need to be evaluated for adequacy due to differences in wheel loading, tire pressure, and undercarriage design. Bridge, tunnel and culvert load bearing capacities may be a limiting factor, requiring some operational procedures. These may require alternative taxi routings where the ACN of the aeroplane exceeds the PCN or the maximum loads of the concerned NLA exceed those used in the design of the underground structures. The Aerodrome Design Manual, Part 3 Pavements (Doc 9157) contains guidance on reporting pavement strength using the ICAO ACN/PCN method. Criteria should be established to regulate the use of a pavement by an aircraft with an ACN higher than the PCN 
reported. It needs to be notices that the ACN-PCN method is meant only for publication of pavement strength data in Aeronautical Information Publications (AIPs). It is not intended for design or evaluation of pavements, nor does it contemplate the use of specific method by the airport authority either for the design or evaluation of pavements. In fact, the ACN-PCN method does permit states to use any design/evaluation method of their choice [1].

AIRBUS S.A.S. Customer Services provided procedures to develop flexible and rigid pavement design, to accommodate A380. The flexible pavement procedure provided by Airbus is based on the US Army Corps of Engineers Design Method. In order to design the flexible pavement; the CBR value, annual departure level, and the weight on one Main Landing Gear must be known. Aircraft A380-800 (NLA), Maximum Takeoff Weight (MTOW) (1,239,000 lbs.) and Wheel Load (58,852 lbs.) [2], A380800 landing gear configuration is shown in Figure 1.

\section{Overload Operations}

Overloading of pavement can result either from loads too large or form substantially increase application rate or both. Loads larger than the defined (design or evaluation load large) load shorten the design life whilst smaller loads extend it. With the excepting of massive overloading, pavements in their structural behavior are not subject to a particular limiting load above which they suddenly or catastrophically fail. Behavior is such that a pavement can sustain a definable load for an expected number of repetitions during its design life. As a result, occasional minor overloading in acceptable when expedient with only limited loss in pavement life expectancy and relatively small acceleration of pavement deterioration. For those operation in which magnitude of overload and or the frequency of use do not justify a detailed analysis the following criteria suggested:

a) For flexible pavement occasional movement by aircraft with ACN not exceeding 10 per cent above the reported PCN should not adversely affect the pavement; b) for rigid or composite pavement, in which a rigid pavement layer provides a primary element of the structure, occasional movements by aircraft with ACN not exceeding 5 percent above, the reported PCN should not adversely affect the pavement; c) If the pavement structure is known the 5 per cent limitation should apply; and d) The annual number of overload movement should not exceed approximately 5 per cent of total annual aircraft movement [3].

Such overload movement should not normally be permitted on pavements exhibiting signs of distress or failure. Furthermore, overloading should be avoided during any periods of thaw following frost penetration or when the strength of the pavement or its sub grade could be weakened by water. Where overload should operation are conduct, the appropriate authority should review the relevant pavement condition regularly and should also review the criteria for overload operations periodically since excessive major rehabilitation of pavement [4].

\section{Using Software}

\subsection{Using (FAARFIELD)}

The Federal Aviation Administration's (FAA) new airport pavement thickness design program, FAArfield (FAA Rigid and Flexible Iterative Elastic Layered Design), is expected to supersede LEDFAA 1.3 as a standard design procedure in the next revision of Advisory Circular (AC) 5320-6. The FAA has made a preliminary version of this program, called FEDFAA, available for download since 2004. Unlike LEDFAA, the FAArfield program incorporates three-dimensional finite element (3D-FE) stress computation for final design of new rigid pavements and rigid overlays. FAARFIELD continues to use LEAF layered elastic analysis for flexible pavement and flexible overlay design, as well as for preliminary design of rigid structures [5].

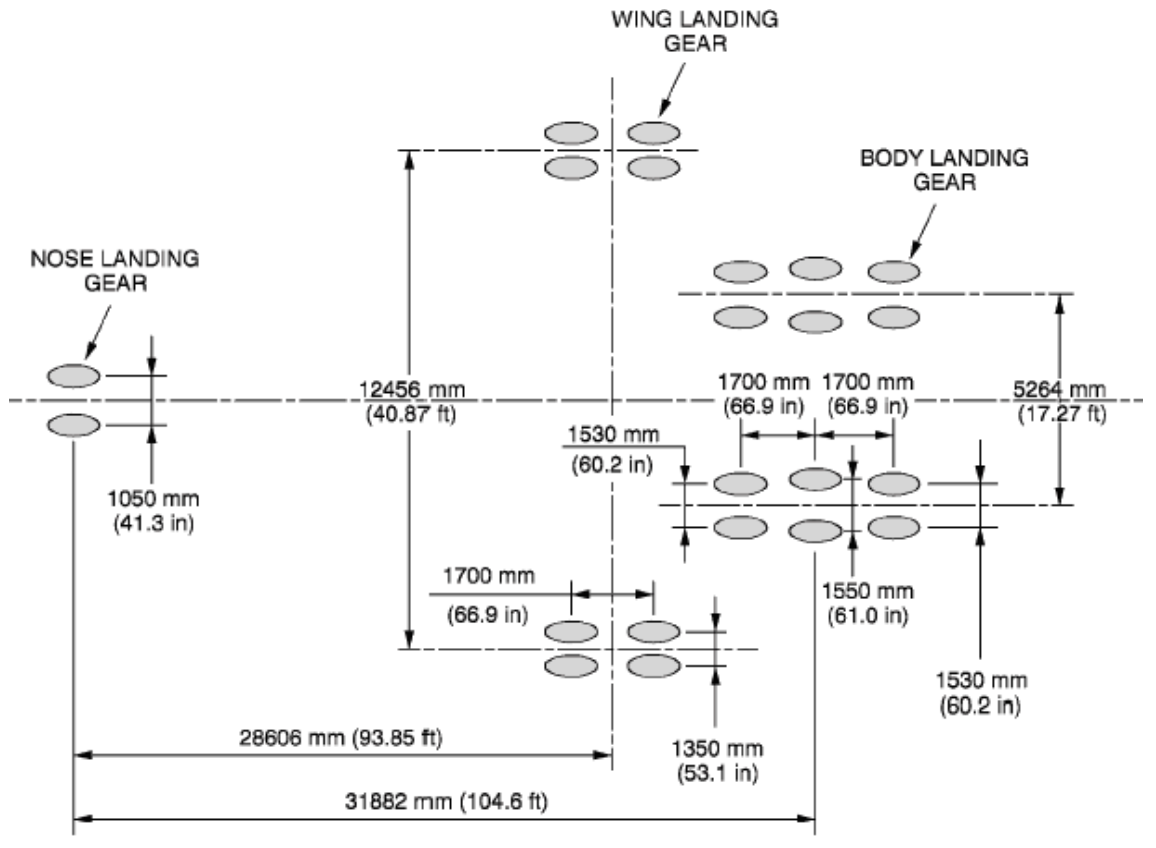

Figure 1. Landing Gear (A380-800) 


\subsection{USING COMFAA Program}

The COMFAA software is a general purpose program that operates in two computational modes: ACN Computation Mode and Pavement Thickness Mode. ACN - A number expressing the relative effect of an aircraft on a pavement for specified standard subgrade strength. PCN - A number expressing the bearing strength of a pavement for unrestricted operations. Therefore, if a particular aircraft at a given weight has an ACN less than, or equal to, the PCN of a particular pavement (ACN $\leq$ PCN), then no restrictions need to be placed on operation of that aircraft on that pavement [5].

Firstly, FAA has been published software called COMFAA 2.0 for computing Acn/Pcn values due to ICAO requirements and many countries used it to evaluating airport pavement and recently, published a new software called COMFAA 3.0 which has big difference in PCN values which made many confusion to airports administration and regulators because it's approved else from ICAO [6].

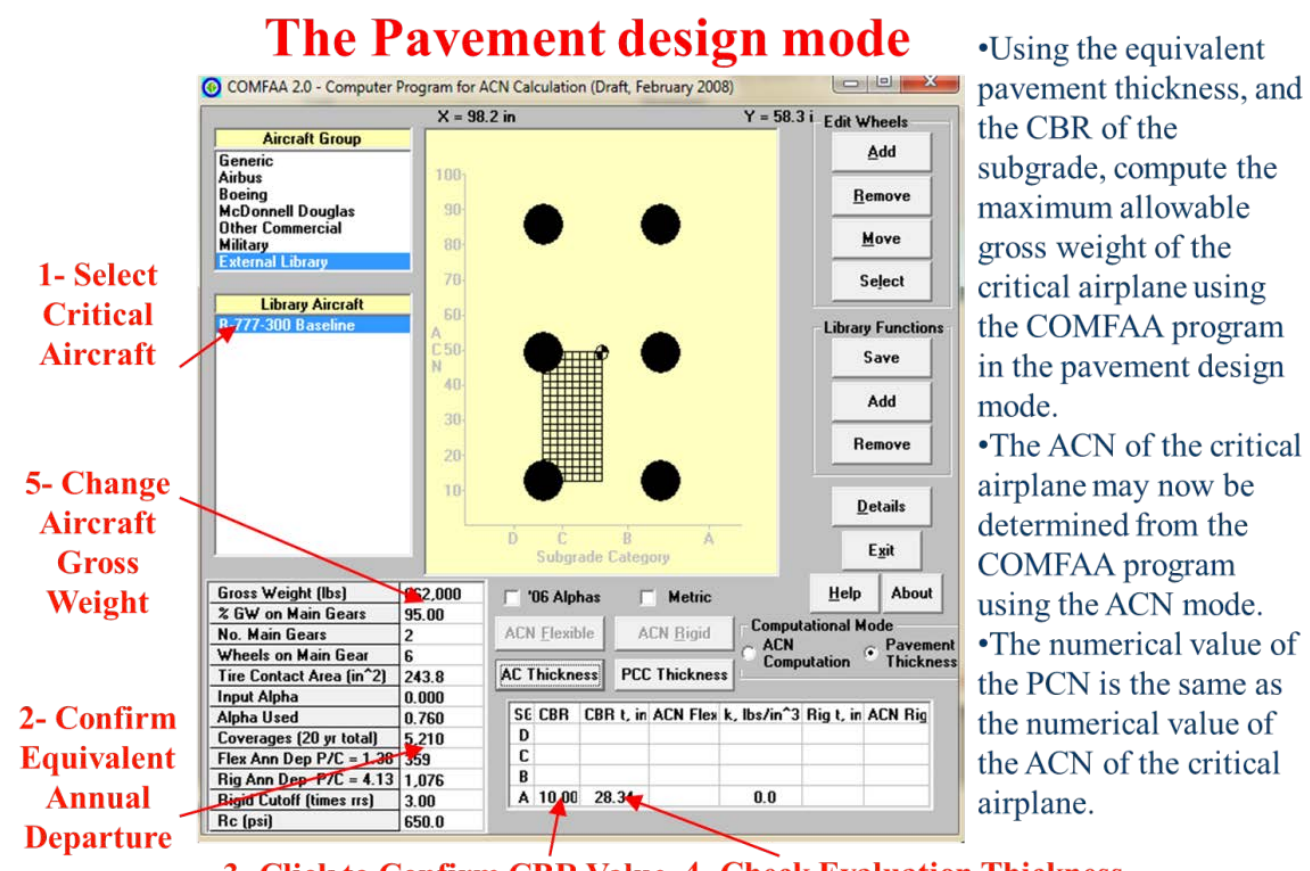

3- Click to Confirm CBR Value 4- Check Evaluation Thickness

Figure 2. PCN Computation by COMFAA 2.0

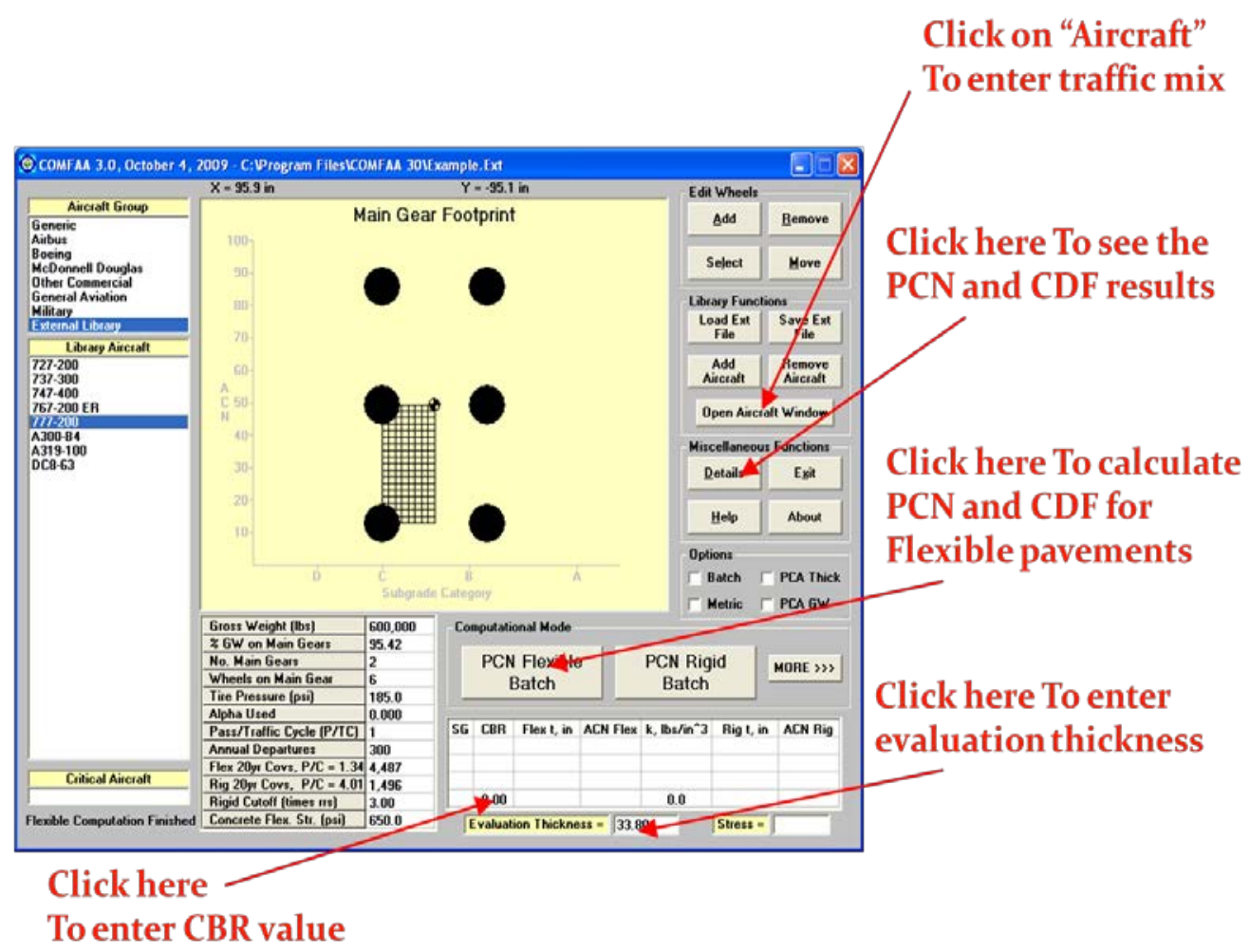

Figure 3. PCN Computation by COMFAA 3.0 


\section{Research Methodology}

Using Hurghada airport air traffic composition data, Hurghada International Airport is an international airport located in the Red Sea City of Hurghada, Egypt. It is the second busiest airport in Egypt after Cairo International Airport. The airport is currently served by one terminal and two runway, so Aircraft movements at Hurghada Runway 16L-34R for the year 2006 are shown in, four levels of assumed annual departures, and four ranges of California Bearing Ratio (CBR) values representing different subgrade soil types, the pavement typical cross section was determined due to 20 years design life. After the introduction of NLA of different percentages of the assumed annual departures levels, the effect on design life of the acquired pavement sections was determined for each of the above cases (By using FAARFIELD and COMFAA 2,3).

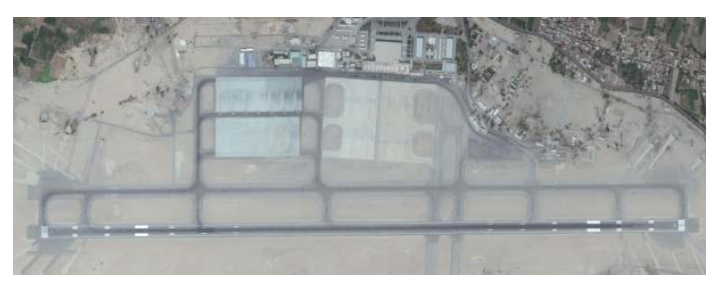

Figure 4. Hurghada International Airport in Egypt
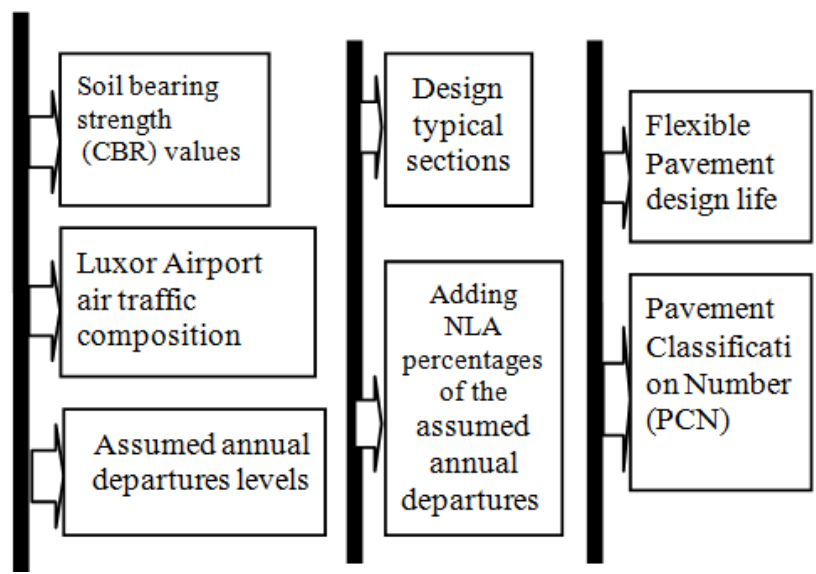

Figure 5. Approach for sensitivity analysis of Pavement Design Life and PCN

Table 1, the data indicates the following

1. Twenty different aircraft types mainly used Hurghada Airport during 2006 with 23,843 annual departures.

2. Gear configuration is an important characteristic that defines the impact of the traffic mix on pavement. Hurghada air traffic mix consists of:

- Three different aircraft types with complex gear configuration representing $2.3 \%$ share in the traffic mix.

- Seven different aircraft types with dual tandem gear configuration representing $24.2 \%$ share in the traffic mix.

- Ten different aircraft type with dual gear configuration representing $73.5 \%$ share in the traffic mix.
Table 1. Annual departure levels for analysis scenarios

\begin{tabular}{|c|c|c|c|c|c|c|}
\hline \multicolumn{3}{|c|}{ Aircraft } & \multicolumn{3}{c|}{ Assumed Annual Departures } \\
\hline No. & type & $\begin{array}{c}\text { \% in } \\
\text { Araffic }\end{array}$ & $\begin{array}{c}10,000 \\
\text { Annual } \\
\text { DEPs }\end{array}$ & $\begin{array}{c}25,000 \\
\text { Annual } \\
\text { DEPs }\end{array}$ & $\begin{array}{c}50,000 \\
\text { Annual } \\
\text { DEPs }\end{array}$ & $\begin{array}{c}100,000 \\
\text { Annual } \\
\text { DEPs }\end{array}$ \\
\hline 1 & B747-200 & 0.12 & 12 & 29 & 59 & 118 \\
\hline 2 & B777-300 & 1.12 & 112 & 279 & 558 & 1117 \\
\hline 3 & A340-200 & 1.04 & 104 & 260 & 521 & 1041 \\
\hline 4 & A330-300 & 0.36 & 36 & 89 & 178 & 357 \\
\hline 5 & A300-B4 & 1.56 & 156 & 389 & 779 & 1557 \\
\hline 6 & B767-200 & 0.38 & 38 & 95 & 191 & 382 \\
\hline 7 & A310-200 & 6.01 & 602 & 1506 & 3012 & 6024 \\
\hline 8 & A310-300 & 15.10 & 1511 & 3778 & 7556 & 15112 \\
\hline 9 & B757-300 & 0.21 & 21 & 52 & 105 & 210 \\
\hline 10 & B757-200 & 0.61 & 61 & 153 & 306 & 613 \\
\hline 11 & A321-200 & 21.39 & 2141 & 5352 & 10704 & 21409 \\
\hline 12 & MD90 & 0.43 & 43 & 108 & 216 & 432 \\
\hline 13 & A320-200 & 29.24 & 2927 & 7317 & 14634 & 29267 \\
\hline 14 & MD83 & 1.79 & 179 & 448 & 896 & 1792 \\
\hline 15 & B737-400 & 0.30 & 30 & 76 & 151 & 302 \\
\hline 16 & B737-500 & 0.08 & 8 & 19 & 38 & 76 \\
\hline 17 & DC9 & 0.41 & 41 & 102 & 204 & 407 \\
\hline 18 & B737-200 & 19.71 & 1973 & 4932 & 9865 & 19730 \\
\hline 19 & G-IV & 0.05 & 5 & 14 & 27 & 55 \\
\hline 20 & LJ35 & 0.09 & 9 & 22 & 44 & 88 \\
\hline
\end{tabular}

Table 2. Base course characteristics for different CBR and annual departure scenarios

\begin{tabular}{|c|c|c|c|c|}
\hline \multirow{2}{*}{$\begin{array}{c}\text { Assumed Annual } \\
\text { Departure }\end{array}$} & \multicolumn{4}{|c|}{ BASE COURSE LAYER THICKNESS (mm) } \\
\cline { 2 - 5 } & CBR=3 & CBR=6 & CBR=10 & CBR=15 \\
\hline 10,000 & $1,021.3$ & 565.4 & 299.8 & 153.0 \\
\hline 25,000 & $1,126.5$ & 634.8 & 339.2 & 186.0 \\
\hline 50,000 & $1,189.2$ & 682.9 & 369.9 & 211.0 \\
\hline 100,000 & $1,242.3$ & 565.4 & 401.2 & 236.3 \\
\hline
\end{tabular}

\subsection{Quantifying NLA Impact on Pavement Design Life.}

Four levels of annual departures are assumed to evaluate pavement performance under different levels of loading. These levels are 10,000 annual departures to represent ultra-low intensity level, 25,000 annual departures to represent low intensity level, 50,000 annual departures to represent medium intensity level, and 100,000 annual departures to represent high intensity level. And four subgrade strength categories are assumed to represent different standard subgrade soil types. These categories are $\mathrm{CBR}=3 \%$ to represent ultra-low strength soil, $\mathrm{CBR}=6 \%$ to represent low strength soil, $\mathrm{CBR}=10 \%$ to represent medium strength soil, and CBR $=15 \%$ to represent high strength soil. The chosen subgrade strength categories in this research are consistent with the categories defined by ICAO for PCN reporting. 


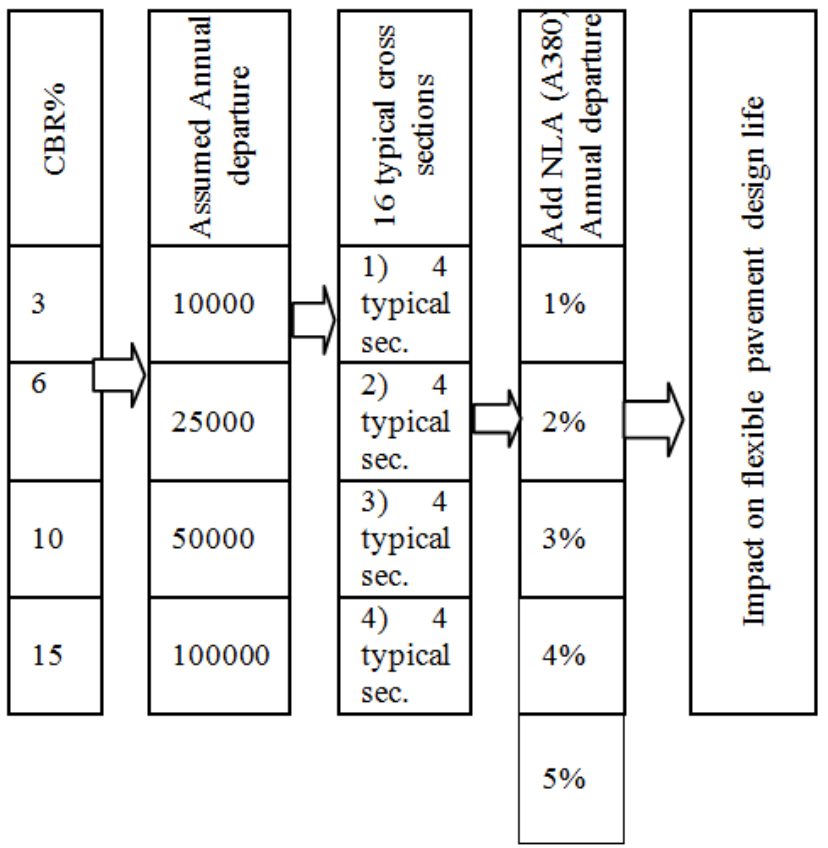

Figure 6. Scenarios for the analysis of NLA impact on pavement life

Sixteen typical cross sections were designed using FAArfield software at the four assumed subgrade strength categories, and the four scenarios of annual departures levels shown in Table 3. Asphalt thickness is taken as a constant and equals to $180.0 \mathrm{~mm}$, and bituminous treated base thickness is also taken as constant and equals to $130.0 \mathrm{~mm}$ for all cases. Crushed aggregate base course thickness and characteristics.

Table 3. ACN values for Air traffic mix for Hurghada airport consists of 20 aircrafts and $\mathbf{A 3 8 0 - 8 0 0}$.

\begin{tabular}{|c|c|c|c|c|c|}
\hline \multicolumn{2}{|c|}{ Aircraft } & \multicolumn{4}{|c|}{ ACN } \\
\hline \multirow{2}{*}{ No. } & type & $\begin{array}{c}\text { At } \\
\text { CBR } \\
=3\end{array}$ & $\begin{array}{c}\text { At } \\
\text { CBR } \\
6\end{array}$ & $\begin{array}{c}\text { At } \\
\text { CBR }= \\
10\end{array}$ & $\begin{array}{c}\text { At } \\
\text { CBR } \\
15\end{array}$ \\
\hline 1 & B747-200 & 58.6 & 64.8 & 53.3 & 48.1 \\
\hline 2 & B777-300 & 100.2 & 72.5 & 58.8 & 52.6 \\
\hline 3 & A340-200 & 88.9 & 65.7 & 56.9 & 52.8 \\
\hline 4 & A330-300 & 98.2 & 72.6 & 62.7 & 57.7 \\
\hline 5 & A300-B4 & 79.7 & 62.8 & 51.6 & 46.3 \\
\hline 6 & B767-200 & 60.4 & 43.8 & 37.5 & 34.5 \\
\hline 7 & A310-200 & 64.8 & 49.5 & 41.1 & 37.1 \\
\hline 8 & A310-300 & 65.8 & 50.5 & 41.8 & 37.7 \\
\hline 9 & B757-300 & 58.1 & 45.1 & 36.6 & 32.9 \\
\hline 10 & B757-200 & 52.9 & 40.3 & 33.0 & 29.7 \\
\hline 11 & A321-200 & 63.2 & 57.6 & 52.0 & 49.4 \\
\hline 12 & MD90 & 55.2 & 52.2 & 48.2 & 44.3 \\
\hline 13 & A320-200 & 50.2 & 44.4 & 40.0 & 38.5 \\
\hline 14 & MD83 & 53.1 & 50.0 & 45.9 & 42.4 \\
\hline 15 & B737-400 & 47.9 & 44.0 & 39.3 & 37.0 \\
\hline 16 & B737-500 & 41.4 & 37.4 & 33.3 & 31.9 \\
\hline 17 & DC9 & 39.3 & 36.5 & 32.4 & 30.6 \\
\hline 18 & B737-200 & 35.1 & 29.9 & 26.5 & 22.4 \\
\hline 19 & G-IV & 25.4 & 24.6 & 23.6 & 22.2 \\
\hline 20 & LJ35 & 5.6 & 5.0 & 4.4 & 4.3 \\
\hline 21 & A380-800 Basic1 Body & 105.7 & 75.1 & 62.0 & 56.1 \\
\cline { 2 - 6 } & A380-800 Basic1 Wing & 102.6 & 75.5 & 63.9 & 58.5 \\
\hline & & & & & \\
\hline
\end{tabular}

\subsection{Quantifying NLA impact on Pavement Classification number (PCN)}

Using Hurghada airport air traffic composition data, four levels of assumed annual departures, and four ranges of California Bearing Ratio (CBR) values representing different subgrade soil types, the PCN for the acquired pavement structure was determined for each case (No NLA cases). Assuming the introduction of A380-800 of different percentages of the assumed annual departures levels, the PCN of the acquired pavement sections was determined for each of the above cases.

\section{Before adding NLA percentages (No NLA cases)}

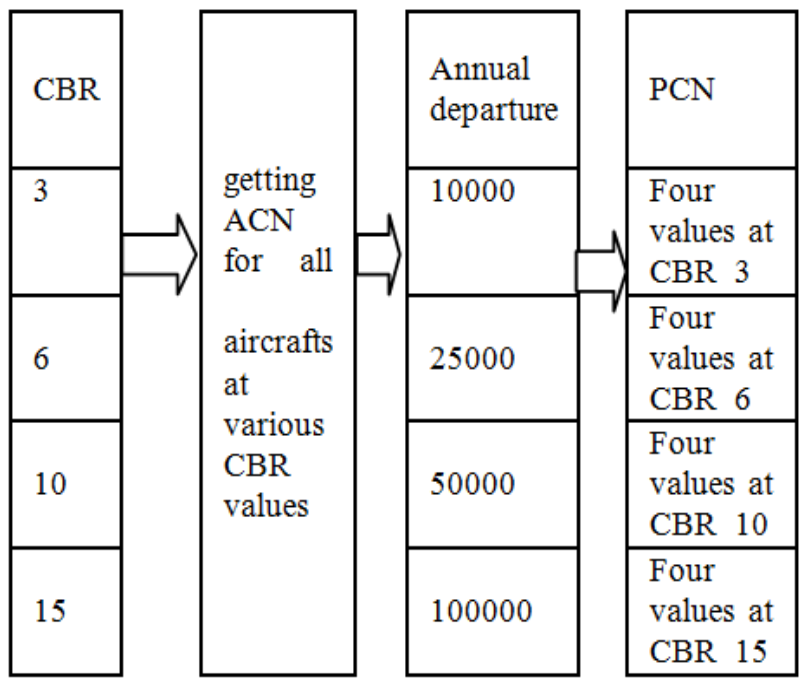

After adding A380-800 percentages

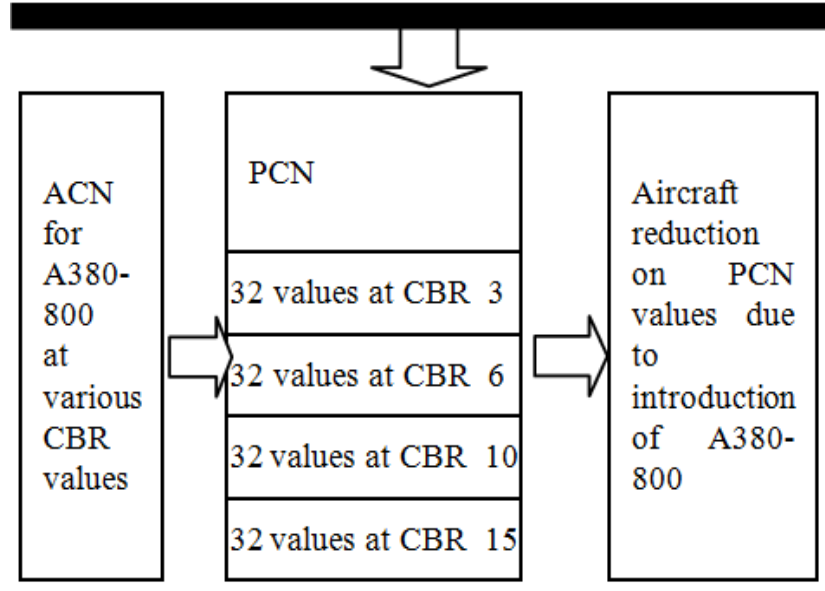

Figure 7. Scenarios for the analysis of NLA impact on PCN

\section{Results \& Discussion}

The study presents the impacts on pavement life due to introduction of A380-800 as a percent share in the traffic mix. The impact on pavement life is studied for four subgrade strength categories and four annual departure levels which were formed using Hurghada Airport air fleet composition. Table 5 shows the results of pavement life analysis scenarios using FAArfield and COMFAA 2,3 for the sixteen typical pavement sections, after the introduction of A380-800 at five percentage share in the traffic mix. 
Table 4. Results of pavement life analysis scenarios

\begin{tabular}{|c|c|c|c|c|c|c|c|}
\hline \multirow{4}{*}{ CBR\% } & \multirow{6}{*}{$\begin{array}{c}\text { Annual } \\
\text { departure }\end{array}$} & \multicolumn{6}{|c|}{ A380-800 Annual departure } \\
\cline { 3 - 8 } & & $0 \%$ & $1 \%$ & $2 \%$ & $3 \%$ & $4 \%$ & $5 \%$ \\
\hline \multirow{4}{*}{3} & 10000 & 20.0 & 12.2 & 6.3 & 4.3 & 3.2 & 2.6 \\
\cline { 2 - 8 } & 25000 & 20.0 & 8.9 & 4.6 & 3.1 & 2.3 & 1.8 \\
\cline { 2 - 8 } & 50000 & 20.0 & 6.3 & 3.2 & 2.1 & 1.6 & 1.3 \\
\cline { 2 - 8 } & 100000 & 20.0 & 4.2 & 2.1 & 1.4 & 1.1 & 0.8 \\
\hline \multirow{4}{*}{6} & 10000 & 20.0 & 17.4 & 15.5 & 13.9 & 12.6 & 11.3 \\
\cline { 2 - 8 } & 25000 & 20.0 & 17.5 & 15.5 & 13.9 & 12.6 & 11.2 \\
\cline { 2 - 8 } & 50000 & 20.0 & 17.5 & 15.5 & 13.9 & 12.6 & 11.1 \\
\cline { 2 - 8 } & 100000 & 20.0 & 17.3 & 15.3 & 13.7 & 12.3 & 11.0 \\
\hline \multirow{4}{*}{10} & 10000 & 20.0 & 17.9 & 16.2 & 14.8 & 13.5 & 12.4 \\
\cline { 2 - 8 } & 25000 & 20.0 & 18.0 & 16.2 & 14.8 & 13.6 & 12.4 \\
\cline { 2 - 8 } & 50000 & 20.0 & 18.0 & 16.3 & 14.8 & 13.5 & 12.4 \\
\cline { 2 - 8 } & 100000 & 20.0 & 17.9 & 16.3 & 14.8 & 13.5 & 12.4 \\
\hline \multirow{4}{*}{15} & 10000 & 20.0 & 17.5 & 15.5 & 13.8 & 12.5 & 11.3 \\
\cline { 2 - 7 } & 25000 & 20.0 & 17.6 & 15.7 & 14.0 & 12.6 & 11.5 \\
\hline & 50000 & 20.0 & 17.6 & 15.7 & 14.1 & 12.7 & 11.6 \\
\hline & 100000 & 20.0 & 17.6 & 15.7 & 14.1 & 12.8 & 11.6 \\
\hline
\end{tabular}

The Table 4 shows that:

- There are two different groups of pavement life behavior, first group contains 3\% CBR, and second group contains CBR values (6\%, 10\%, and 15\%)

- With the change of annual departure levels, pavement life behavior shows the same two different groups of pavement life behavior, first group contains $3 \% \mathrm{CBR}$, and second group contains CBR values (6\%, 10\%, and 15\%)

- Changes in pavement life for the four annual departure levels have almost the same behavior at CBR Values (6\%, 10\%, and 15\%) which ranges between $(0.0 \%$ and $1.5 \%)$.

The Table 5, Table 6 and Figure 6, Figure 7, Figure 8, Figure 9 shows that:-

- There is no impact for adding aircraft A380-800 annual departure at CBR 6, $10,15 \%$ at any total annual departure using COMFAA 2

- There is no impact for adding aircraft A380-800 annual departure at CBR $3 \%$ except at annual departure 10000 and 25000 using COMFAA 2

- The major impact for adding aircraft A380-800 annual departure at CBR 3, 6 \% using COMFAA 3

- There is no impact for adding aircraft A380-800 annual departure at CBR $15 \%$ at annual departure 50000 and 100000 using COMFAA 3

- There is no restriction for adding aircraft A380-800 annual departure up to $5 \%$ to air traffic mix due to COMFAA 2 or 3.

Table 5. Results of Pavement Classification Number (PCN) analysis scenarios using COMFAA 3.0

\begin{tabular}{|c|c|c|c|c|c|c|c|c|}
\hline \multirow{3}{*}{ CBR } & \multirow{3}{*}{$\begin{array}{l}\text { ACN for NLA } \\
\text { (A380-800) } \\
\text { Basic1 Wing }\end{array}$} & \multirow{3}{*}{$\begin{array}{c}\text { Annual } \\
\text { departure }\end{array}$} & \multicolumn{6}{|c|}{ PCN by CBR Using COMFAA 3.0 design method } \\
\hline & & & \multicolumn{6}{|c|}{ NLA (A380-800) annual departure } \\
\hline & & & $0 \%$ & $1 \%$ & $2 \%$ & $3 \%$ & $4 \%$ & $5 \%$ \\
\hline \multirow{4}{*}{3} & \multirow{4}{*}{102.6} & 10000 & 128.9 & 118.10 & 112.30 & 108.80 & 106.40 & 104.70 \\
\hline & & 25000 & 148.2 & 129.80 & 122.10 & 117.80 & 114.80 & 112.70 \\
\hline & & 50000 & 159.2 & 137.50 & 129.30 & 124.90 & 122.00 & 119.80 \\
\hline & & 100000 & 159.7 & 140.80 & 133.10 & 128.90 & 126.00 & 123.90 \\
\hline \multirow{4}{*}{6} & \multirow{4}{*}{75.5} & 10000 & 125.3 & 121.50 & 112.50 & 107.20 & 103.50 & 100.80 \\
\hline & & 25000 & 138.9 & 130.80 & 120.10 & 114.40 & 110.60 & 107.80 \\
\hline & & 50000 & 143 & 133.40 & 122.60 & 117.10 & 113.60 & 111.00 \\
\hline & & 100000 & 135.3 & 135.60 & 125.30 & 120.00 & 116.80 & 114.40 \\
\hline \multirow{4}{*}{10} & \multirow{4}{*}{63.9} & 10000 & 90.2 & 92.10 & 89.40 & 87.00 & 85.70 & 84.40 \\
\hline & & 25000 & 85.4 & 90.30 & 88.70 & 87.40 & 86.30 & 85.40 \\
\hline & & 50000 & 82.8 & 86.50 & 85.90 & 85.40 & 85.00 & 84.50 \\
\hline & & 100000 & 84.4 & 84.40 & 84.30 & 84.30 & 84.20 & 84.10 \\
\hline \multirow{4}{*}{15} & \multirow{4}{*}{58.5} & 10000 & 81 & 82.70 & 81.10 & 79.40 & 78.80 & 77.90 \\
\hline & & 25000 & 77.9 & 78.90 & 78.50 & 78.10 & 77.70 & 77.40 \\
\hline & & 50000 & 79.20 & 79.20 & 79.20 & 79.20 & 79.20 & 79.20 \\
\hline & & 100000 & 81.20 & 81.20 & 81.20 & 81.20 & 81.20 & 81.20 \\
\hline
\end{tabular}


Table 6. Results of Pavement Classification Number (PCN) analysis scenarios using COMFAA 2.0

\begin{tabular}{|c|c|c|c|c|c|c|c|c|}
\hline \multirow{3}{*}{ CBR } & \multirow{3}{*}{$\begin{array}{c}\text { ACN for NLA } \\
\text { (A380-800) } \\
\text { Basic1 Wing }\end{array}$} & \multirow{3}{*}{$\begin{array}{c}\text { Annual } \\
\text { departure }\end{array}$} & \multicolumn{6}{|c|}{ PCN by CBR Using COMFAA 2.0 design method } \\
\hline & & & \multicolumn{6}{|c|}{ NLA (A380-800) annual departure } \\
\hline & & & $0 \%$ & $1 \%$ & $2 \%$ & $3 \%$ & $4 \%$ & $5 \%$ \\
\hline \multirow{4}{*}{3} & \multirow{4}{*}{102.6} & 10000 & 128.40 & 116.40 & 113.20 & 111.90 & 110.30 & 99.40 \\
\hline & & 25000 & 104.50 & 102.90 & 102.40 & 102.10 & 102.00 & 101.80 \\
\hline & & 50000 & 105.30 & 105.30 & 105.30 & 105.30 & 105.30 & 105.30 \\
\hline & & 100000 & 110.10 & 110.10 & 110.10 & 110.10 & 110.10 & 110.10 \\
\hline \multirow{4}{*}{6} & \multirow{4}{*}{75.5} & 10000 & 84.40 & 84.40 & 84.40 & 84.40 & 84.40 & 84.40 \\
\hline & & 25000 & 90.40 & 90.40 & 90.40 & 90.40 & 90.40 & 90.40 \\
\hline & & 50000 & 95.90 & 95.90 & 95.90 & 95.90 & 95.90 & 95.90 \\
\hline & & 100000 & 102.40 & 102.40 & 102.40 & 102.40 & 102.40 & 102.40 \\
\hline \multirow{4}{*}{10} & \multirow{4}{*}{63.9} & 10000 & 78.50 & 78.50 & 78.50 & 78.50 & 78.50 & 78.50 \\
\hline & & 25000 & 83.40 & 83.40 & 83.40 & 83.40 & 83.40 & 83.40 \\
\hline & & 50000 & 89.70 & 89.70 & 89.70 & 89.70 & 89.70 & 89.70 \\
\hline & & 100000 & 94.90 & 94.90 & 94.90 & 94.90 & 94.90 & 94.90 \\
\hline \multirow{4}{*}{15} & \multirow{4}{*}{58.5} & 10000 & 76.20 & 76.20 & 76.20 & 76.20 & 76.20 & 76.20 \\
\hline & & 25000 & 83.10 & 83.10 & 83.10 & 83.10 & 83.10 & 83.10 \\
\hline & & 50000 & 88.50 & 88.50 & 88.50 & 88.50 & 88.50 & 88.50 \\
\hline & & 100000 & 100.70 & 100.70 & 100.70 & 100.70 & 100.70 & 100.70 \\
\hline
\end{tabular}

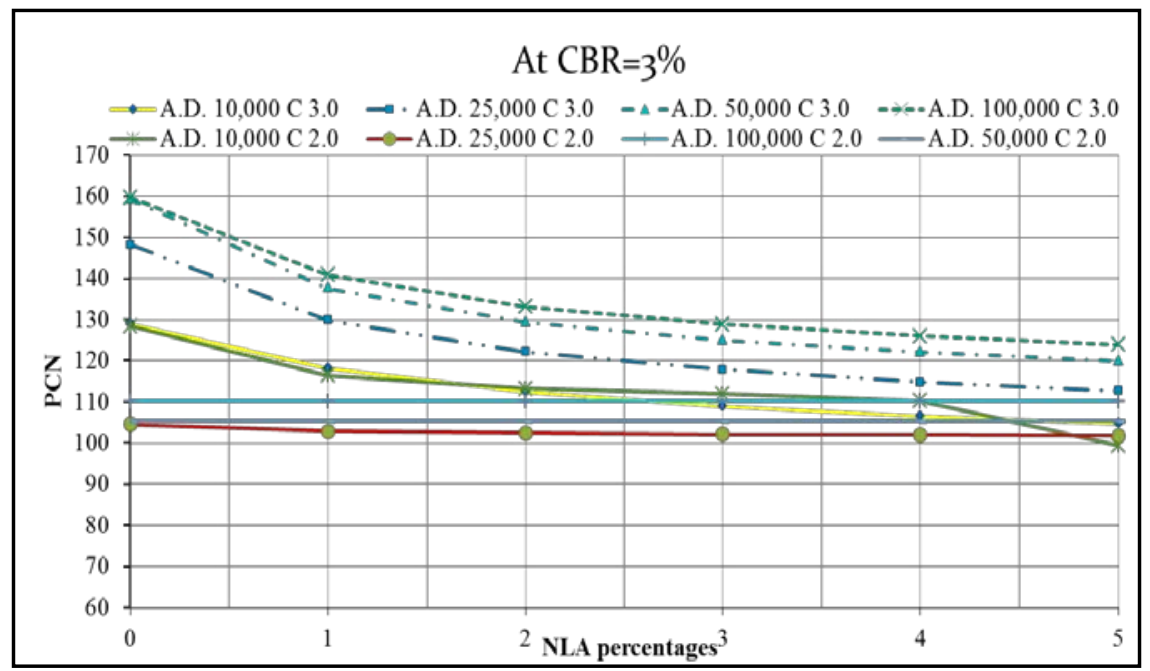

Figure 8. Results of Pavement Classification Number (PCN) analysis scenarios at CBR = 3\%, using COMFAA 2.0 vs COMFAA 3.0

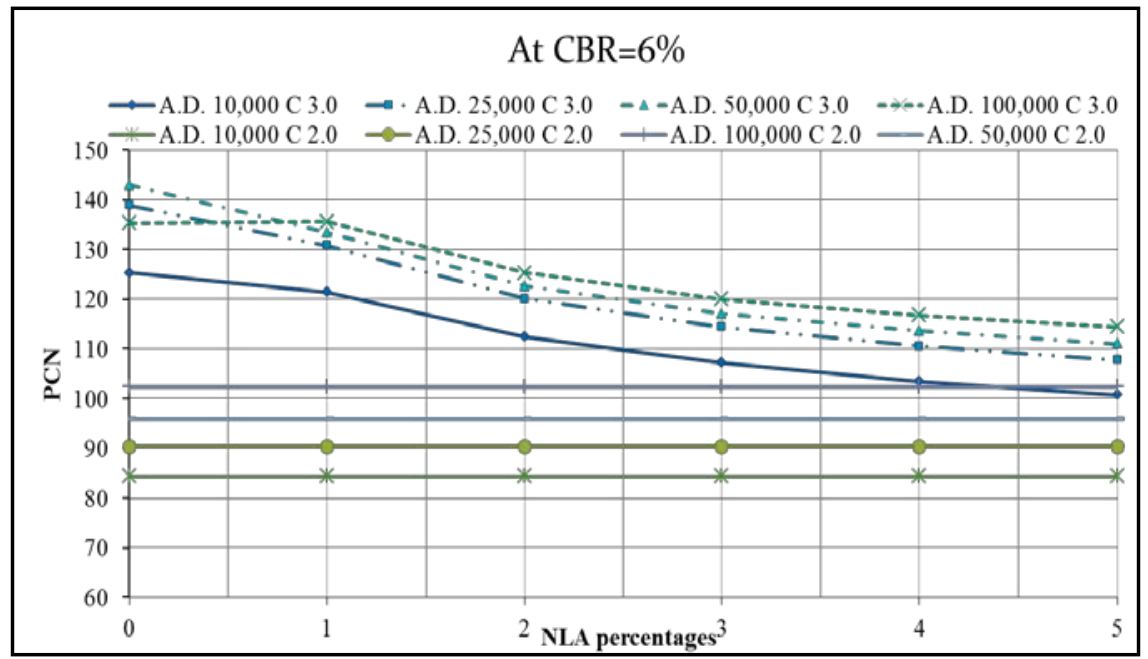

Figure 9. Results of Pavement Classification Number (PCN) analysis scenarios at CBR =6\%, using COMFAA 2.0 vs COMFAA 3.0 


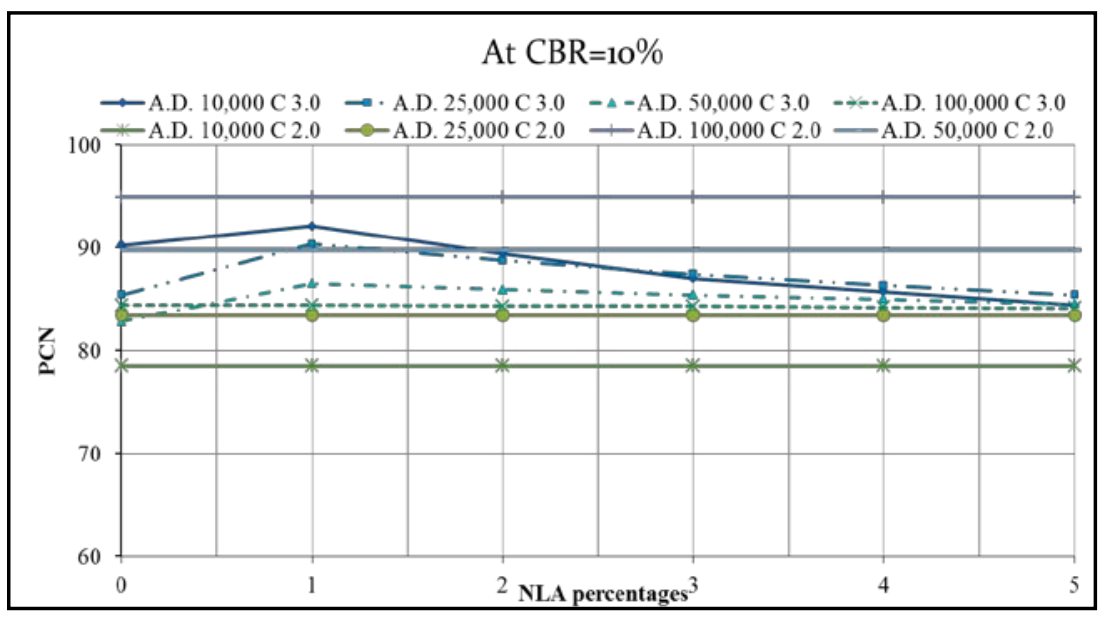

Figure 10. Results of Pavement Classification Number (PCN) analysis scenarios at CBR $=10 \%$, using COMFAA 2.0 vs COMFAA 3.0

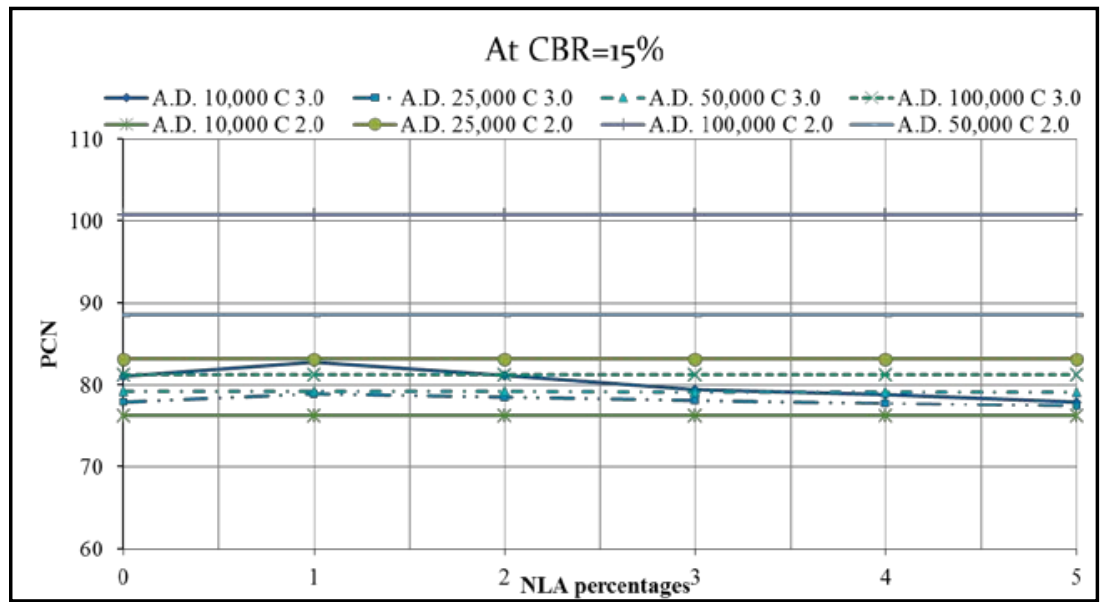

Figure 11. Results of Pavement Classification Number (PCN) analysis scenarios at CBR $=15 \%$, using COMFAA 2.0 vs COMFAA 3.0

\section{Conclusions}

\subsection{Main Goals}

Based on the study results and analysis the following conclusion was obtained from this research:-

- The statement in ICAO Practice "the annual number of overload movement should not exceed approximately 5 per cent of total annual aircraft movement" must be re-evaluated due to many factors as new large aircraft type, annual departures and soil characteristics which High reduction in pavement life that has an average of $8.2 \%$ of 20 years design life due to introduction of A380-800 by $5 \%$ of annual departures, occurred at 3\% CBR.

- The statement in ICAO Practice "For flexible pavement occasional movement by aircraft with ACN not exceeding 10 per cent above the reported PCN should not adversely affect the pavement" must be re-evaluated because there is no restriction for adding new large aircraft with 5\% Annual departure at any annual departures, soil characteristics comparing between COMFAA 2,3 software .which High reduction in pavement life that has an average of $8.2 \%$ of 20 years design life due to introduction of A380-800 by $5 \%$ of annual departures, occurred at $3 \% \mathrm{CBR}$.
- New methodology for ACN - PCN method should be conducted to correlate with new concept for pavement life (FAArfield). Because Acn values relate to CBR Design method and Pcn relate to thickness conducted from new pavement design products like FAARFIELD1.3 which thickness lower than CBR design method.

\subsection{Others}

- The rate of reduction in pavement life due to introduction of A380-800 up to 5\% of annual departure is almost the same at CBR equal or higher than $6 \%$ at various annual departure levels $(10,000$, 25,000, 50,000, and 100,000 annual departures).

- The change in pavement life percentage is linear in case of introduction of A380-800 at $2 \%$ up to $5 \%$ of annual departure.

- Annual departure level is directly proportional to reduction in pavement life due to A380-800 introduction at 3\% CBR value.

- At subgrade strength equal to or higher than $6 \%$ CBR, the pavement life reduction due to NLA introduction is almost the same at different levels of annual departures.

- Change in PCN did not show any restriction at 3\% CBR however, there is a great reduction in 
pavement life that has an average of $8.2 \%$ of 20 years design life due to introduction of A380-800.

- PCN reduction values are directly proportional with to annual departure levels.

- There is big difference between COMFAA2 and COMFAA3 software in PCN output and must be re-evaluated by FAA.

\section{References}

[1] ICAO - International Civil Aviation Organization. (2004). Circular on New Larger Aeroplane Operations at Existing Aerodromes, Cir 305 - AN/177.
[2] Airbus (2015). A global route network for A380s in airline service. Retrieved June 6, 2016,

http://www.airbus.com/aircraftfamilies/passengeraircraft/a380fami ly/a380-routes/.

[3] ICAO - International Civil Aviation Organization. (1983). Aerodrome Design Manual. Part 3 Pavements, (2nd Ed.). Doc. 9157-AN/901, Part 3.

[4] Shafabakhsh, G.A. \& Kashi, E. (2014). Effect of Aircraft Wheel Load and Configuration on Runway Damages. International Journal of Damage Mechanics, 59(1), pp. 85-94, 2015.

[5] Federal Aviation Administration. (2009). Advisory Circular 150/5320-6E, Airport Pavement Design and Evaluation. $<$ http://www.faa.gov/>.

[6] Bayoumi, M. "Study of the Impact of New Large Aircraft (NLA) on Airport Flexible Pavement” Master's thesis, Cairo University, 2015. 